\title{
ORÍGENES Y PRINCIPALES EXPONENTES DEL LAICISMO, EN SU VERTIENTE EDUCATIVA, EN CHILE \\ DOI: http://dx.doi.org/10.1590/2236-3459/68613
}

\author{
Jaime Caiceo Escudero \\ Universidad de Santiago de Chile, Chile.
}

$\cos 80$

\begin{abstract}
Resumen
El objeto de este artículo es describir el surgimiento del laicismo en Chile en la segunda mitad del siglo 19. Luego se destacan las figuras más señeras en esa línea en la primera mitad del siglo 20 , especialmente por haber aportado la pedagogía de Dewey al desarrollo educacional del país, superando las influencias francesas y alemanas que durante el siglo 19 habían iluminado el quehacer laico y educativo; lo anterior se, complementa con el pensamiento laico presente en los Premios Nacionales de Educación de ese sector y relacionarlos con la pedagogía de Dewey; ellos son importantes exponentes de la educación pública de la segunda mitad del siglo pasado en el país. En todo este proceso no estuvo exenta la existencia de debates con representantes de sectores afines a la Iglesia Católica.

Palabras-clave: laicismo educacional, escuela nueva, controversias laicismo-catolicismo, principales exponentes laicos.

\section{ORIGINS AND LEADING EXPONENTS OF SECULARISM, IN ITS EDUCATIONAL ASPECT, IN CHILE}

\section{Abstract}

The object of this article is to describe the emergence of secularism in Chile in the second half of the $19^{\text {th }}$ century. Afterwards, it highlights the most outstanding figures in this line in the first half of the $20^{\text {th }}$ century, especially for bringing the pedagogy of Dewey's educational into the development of the country, beating the French and German influences during the $19^{\text {th }}$ century had lit up the secular and educational work; the above is, complemented by the present secular thought present in the National Education Awards of this field to be related with the pedagogy proposed by Dewey; they are important exponents of public education in the second half of the last century in the country. This process was carried out in the middle of discussions with representatives of sectors related to the Catholic Church.

Key-words: educational secularism, new school, laicism controversies catholicism, main secular exponents. 


\section{ORIGENS E PRINCIPAIS EXPOENTES DO LAICISMO, EM SUA VERTENTE EDUCATIVA, NO CHILE}

\section{Resumo}

O objetivo deste artigo é descrever o surgimento do laicismo no Chile na segunda metade do século 19. Em seguida destacam-se as figuras mais proeminentes nessa linha na primeira metade do século 20, especialmente por haverem aportado a pedagogia de Dewey ao desenvolvimento educacional do país, superando as influências francesas e alemãs que, durante o século 19, haviam iluminado o proceder laico e educativo. Complementa-se com a descrição do pensamento laico presente nos Prêmios Nacionais de Educação e a relação com a pedagogia de Dewey, que são importantes expoentes da educação pública da segunda metade do século passado no país. Todo esse processo não esteve isento da existência de debates com representantes de setores afins à Igreja Católica.

Palavras-chave: laicismo educacional, escola nova, controvérsias laicismo-catolicismo, principais expoentes laicos.

\section{ORIGINES ET PRINCIPAUX REPRESENTANTS DE LA LAÏCITE DANS SON ASPECT ÉDUCATIF AU CHILI}

\section{Résumé}

Le but de cet article est de décrire l'émergence de la laïcité au Chili dans la deuxième moitié du 19ème siècle. Puis met en évidence les figures les plus remarquables de cette ligne dans la première moitié du 20e siècle, en particulier pour amener la pédagogie de Dewey au développement de l'éducation du pays, en battant les influences françaises et allemandes au cours du 19ème siècle, ils avaient allumé le travail séculaire et éducatif; ci-dessus est, complétée par la pensée laïque présente aux Prix National de I 'Éducation cette secteur et concernent la pédagogie de Dewey; ils sont des exposants très importants de l'éducation publique dans la seconde moitié du siècle dernier dans le pays. Dans ce processus, il ne fut pas sans l'existence de discussions avec les représentants des secteurs liés à l'Église catholique.

Mots-clés: laïcité éducationnel, nouvelle école, les controverses de la laïcité-catholicisme, les principaux exposants laïques. 


\section{Introducción}

a educación pública se inicia en Chile prácticamente con la República en el siglo $19^{1}$, destacándose especialmente la labor de Manuel Montt, primero como ministro de Justicia, Culto e Instrucción Pública del presidente Manuel Bulnes (1841-1851) y luego como Presidente de Chile (1851-1861). Con su gestión comienza propiamente el pensamiento laico en educación, acuñando este sector como propio el concepto de estado docente ${ }^{2}$, el cual tuvo como contrapartida el de la libertad de enseñanza ${ }^{3}$ por parte de los sectores ligados a la Iglesia Católica.

En este artículo se profundizará el origen del laicismo ${ }^{4}$ en el país, el cual surge durante el siglo 19, orientado principalmente hacia la educación. Posteriormente, se analizará el fundamento pedagógico y la acción de los tres principales representante que hubo en la primera mitad del siglo pasado, quienes continuando con una línea de pensamiento educativo laico, cambiaron los principios orientadores racionalistas y positivistas del siglo anterior por la pedagogía de John Dewey, es decir, los educadores chilenos laicos, en vez de nutrirse de Europa, comenzaron a mirar hacia los Estados Unidos de América. Los representantes que serán estudiados, a su vez, están ligados al Instituto Pedagógico de la Universidad de Chile, entidad pública y de inspiración laica.

${ }^{1}$ El 18 de septiembre de 1810 se establece la primera Junta de Gobierno en vistas de la proclamación de la
independencia que se concreta el 12 de febrero de 1818. Entre ese año y la constitución de 1833 se
produce el período de consolidación del Chile independiente; se proponen diversas normas
constitucionales (1813, 1818, 1823 y la mencionada de 1833) y existe inestabilidad política; se suceden
gobiernos. Sin embargo, ello fue solo de poco más de una década, pues se puede hablar propiamente del
inicio de la República con el inicio del régimen conservador en 1831, pero se consolida con la constitución
ya mencionada, obra de Diego Portales.

2 Este concepto se constituye desde la promulgación de la Ley General de Instrucción Primaria en 1860. Se entiende por estado docente, a partir de esa ley, que el estado debe ser el responsable de la educación y entregarla gratuitamente en su etapa inicial. Paradojalmente, la misma ley reconoce la libertad de enseñanza. Se afianza mucho más la noción de estado docente con la promulgación de la Ley de Instrucción Primaria Obligatoria en 1920, con la cual el estado debía garantizar que niñas y niños tuvieran acceso a la educación primaria gratuita (Biblioteca Nacional de Chile, 2015b; Cristián Cox et al., 1997 y Miguel Amunátegui, 1856).

${ }^{3}$ A partir del término de la Independencia en Chile (1818), el nuevo estado comenzó a fundar sus propias escuelas, cuyo monopolio lo había tenido la Iglesia Católica durante la colonia. En la medida que el estado avanzaba en la consolidación de la educación pública, laica y gratuita, concretando el denominado estado docente, la Iglesia Católica comenzó a luchar por la libertad de enseñanza, la cual significaba que debían existir también escuelas privadas regidas por ella con el objeto de resguardar la posibilidad de los padres de elegir entre la educación estatal y la privada. Además la ley de 1860 le reconocía tal derecho (AedoRichmond, 2000).

${ }^{4}$ Chile, como ex colonia española, estaba enraizado en una cultura religiosa católica y en las constituciones mencionadas en la nota 1 se señala expresamente que la única religión aceptada era la católica para el estado y sus ciudadanos. El liberalismo venido de Europa hará que lentamente se vaya colocando al estado en una posición independiente de lo religioso, pero ello será un largo camino - como se verá en esta exposición -, iniciado especialmente en el rol que el estado va asumiendo frente a la educación desde 1860 en adelante. La Sociedad de la Igualdad - que se expondrá más adelante - hará un gran aporte para establecer una sociedad laica en el país; las leyes laicas dictadas entre 1883 y 1884 serán un avance al respecto. La consolidación del estado laico se establece con la separación de la Iglesia y el Estado en la constitución de 1925. En este artículo se insistirá más bien en la educación laica, la cual entendía que el estado era el responsable de la educación, estado docente, pública y gratuita para sus niños, niñas y jóvenes (dirección de Bibliotecas, Archivos y Museos, 2015).

\begin{tabular}{|l|l|l|l|l|l|}
\hline Hist. Educ. (Online) & Porto Alegre & v. 21 & n. 51 & Jan./abr., 2017 & p. 333-350 \\
\hline
\end{tabular}




\section{Origen del laicismo en Chile}

Tal como se indicó en la Introducción, el laicismo comienza a tener sus orígenes a partir de la década del 30 del siglo 19. Inmediatamente se da una resistencia con los grupos conservadores, especialmente ligados a la Iglesia Católica. Por lo mismo, la segunda mitad de ese siglo se destaca por las luchas permanentes entre representantes de ambos sectores. Esta controversia entre los defensores de una y otra posición (estado docente vs. libertad de enseñanza) ha estado presente en los diferentes debates que ha habido a lo largo del siglo y medio de su vigencia; ellos han surgido especialmente por la ideologización de las posiciones; en efecto, los defensores del estado docente han enfatizado la laicización del estado a partir de una educación y una cultura laicas; los segundos han defendido el catolicismo a partir de la libertad de enseñanza.

La mayor controversia se dio precisamente en la segunda mitad del siglo 19 en el país cuando los defensores del laicismo tenían su propio medio de difusión, el diario El Ferrocarril, desde donde no solo difundían sus ideas liberales sino que se dedicaban a atacar a los católicos y a proponer la instauración de un estado laico; estos últimos, a su vez, desde su propio diario, El Estandarte Católico, hacían sus planteamientos, rebatían los ataques de los primeros y contraatacaban señalando que Chile era un país católico. Como una reacción a esta situación, el gobierno liberal de Santa María dictó una serie de leyes, denominadas laicas: ley de cementerios, ley de matrimonio civil y registro civil (1883-1884). Hasta entonces existían solo los cementerios parroquiales católicos, los matrimonios por la Iglesia y la inscripción de los recién nacidos en el libro de partida de bautismos en las parroquias, previa ceremonia sacramental. Esta situación era el inicio de la separación de la Iglesia del Estado que se producirá en el siglo siguiente. El clímax de esta controversia se dio con el control ideológico de la Universidad de Chile por los laicistas y por la creación y control ideológico de los católicos de la Universidad Católica de Chile, que se funda en 1888 (Krebs et al., 1981).

Años antes se había dado otra muestra de la controversia entre laicistas y católicos; en efecto, en 1856, Claudio Matte, gran exponente del pensamiento laico, fundó la Sociedad de Instrucción Primaria, la cual aún existe, con el objeto de entregar educación particular gratuita con un pensamiento laico; la Iglesia Católica no se dejó estar y en 1870 fundó la Asociación de Escuelas Santo Tomás de Aquino con el mismo objetivo de las anteriores (educación particular y gratuita), pero con una clara orientación confesional; en un comienzo la orientación era hacia la educación primaria y hacia talleres laborales; esta Asociación aún existe (Caiceo, 2009).

La concreción del estado docente fue posible porque al finalizar el primer gobierno pelucón de Prieto (1831-1841) y, afianzada la República con gobiernos democráticos, comenzaron a llegar al país una serie de escritores, educadores y políticos de otros países latinoamericanos que no aceptaban los caudillismos allí existentes o porque veían que en Chile podían desarrollar mejor sus intereses intelectuales. Es así, como arriban personalidades como Andrés Bello, venezolano; Domingo Faustino Sarmiento y Federico Álvarez de Toledo, argentinos y varios más. También llegan personalidades europeas, invitadas por el gobierno de Chile; entre ellos cabe destacar a los franceses Claudio Gay y Ambrosio Lozier; los españoles José Joaquín de Mora, Andrés Antonio de Gorbea y José León Cabezón; el polaco Ignacio Domeyko (Celis, 2015). Al igual que esas personas que traían ideas progresistas para la época, comenzaron a llegar las ideas europeas ligadas a 
la masonería y al pensamiento libertario; todo ello fue conformando lo que pasó a llamarse el laicismo; varias de las personalidades que arribaron al país eran masones y ello posibilitó que el 27 de julio de 1853 se fundara en Valparaíso la primera Logia propiamente chilena, llamada Logia Unión Fraternal n. (Socías, 2002). Producto del nuevo ambiente intelectual reinante, surge en el país el movimiento literario e intelectual, conocido como la generación de 1842; entre ellos, liderado por José Victorino Lastarria, se destacan Francisco Bilbao, Santiago Arcos, Salvador Sanfuentes, José Joaquín Vallejos, Antonio García Reyes, Eusebio Lillo, José Ramírez Rosales, Manuel Caro y muchos otros, de nacionalidad chilena (Stuven, 1987). En este grupo también hubo argentinos, como Domingo Faustino Sarmiento y Juan Bautista Alberdi.

A partir de este grupo se forma la Sociedad de la lgualdad en 1850, teniendo como base el Club de la Reforma; sus líderes son Santiago Arcos y Francisco Bilbao; asumen un liberalismo más radical, planteando una verdadera transformación revolucionaria de la sociedad para dar paso a una nación de hombres libres; este grupo de intelectuales, por primera vez, busca alianzas con sectores populares (Zapiola, 1902; Biblioteca Nacional de Chile, 2015b).

Paralelamente a lo anterior y con participación de varios de los nombres mencionados, en el ámbito educativo surgen tres importantes instituciones señeras de la educación laica chilena, como obras del estado y en función de su misión de preocuparse de la educación pública en forma preferente. En efecto, en 1842 se fundan la Universidad de Chile (Mellafe et al., 1992) y la primera Escuela de Preceptores, dirigidas por Andrés Bello y Domingo Faustino Sarmiento, respectivamente. La base de la universidad fue la Real Universidad de San Felipe, fundada durante la colonia (1747).

El rector Andrés Bello, en el discurso inaugural del inicio de las actividades de la Universidad de Chile, pronunciado el 18 de septiembre de 1843, indicaba:

Con la asistencia del consejo, con la actividad ilustrada y patriótica de las diferentes facultades; bajo los auspicios del gobierno, bajo la influencia de la libertad, espíritu vital de las instituciones chilenas, me es lícito esperar que el caudal precioso de ciencia y talento, de que ya está en posesión la Universidad, se aumentará, se difundirá velozmente, en beneficio de la religión, de la moral, de la libertad misma, y de los intereses materiales. [...] La Universidad, señores, no sería digna de ocupar un lugar en nuestras instituciones sociales, si (como murmuran algunos ecos oscuros de declamaciones antiguas) el cultivo de las ciencias y de las letras pudiese mirarse como peligroso bajo un punto de vista moral, o bajo un punto de vista político. La moral (que yo no separo de la religión) es la vida misma de la sociedad; la libertad es el estímulo que da un vigor sano y una actividad fecunda a las instituciones sociales. (Bello, 1843, p. 5)

En estos dos pasajes del discurso, se percibe el espíritu profundamente humanista de Andrés Bello, unido a su deseo de cultivar la ciencia, uniéndola con la moral y la religión.

La fundación de esta primera universidad pública en el país es un hito fundamental en la historia de la educación del siglo 19 y en el nacimiento de la clase profesional en el país. No obstante, el acceso a la instrucción universitaria estuvo vedado para la población femenina la mayor parte del siglo 19, periodo en el cual aquella contaba con escasas alternativas educativas (Biblioteca Nacional de Chile, 2015a). En el mismo decreto de 
fundación se establece que esta institución, junto al Instituto Nacional ${ }^{5}$, serán las que ejercerán el rol de la Superintendencia General de Educación - establecida en la constitución de 1833 -, debiendo supervisar y controlar con exámenes a los alumnos de la enseñanza secundaria particular. Esta situación alimentó las disputas entre los defensores del estado docente versus los de la libertad de enseñanza.

Por su parte, el ministro de Justicia, Culto e Instrucción Pública, Manuel Montt, el 18 de enero de 1842 dicta el decreto, que crea la primera Escuela de Preceptores ${ }^{6}$; en art.1 señala: "Se establece en Santiago una escuela normal para la enseñanza e instrucción de las personas que han de dirigir las escuelas primarias en toda la extensión de la República" (Soto, 2000, p. 28). A su vez, en su art. 2, se indica que

se enseñarán los ramos siguientes: leer y escribir con perfección y un conocimiento completo de los métodos de enseñanza mutua y simultánea; dogma y moral religiosa; aritmética comercial; gramática y ortografía castellana; geografía descriptiva; dibujo lineal; nociones generales de historia y particulares de la de Chile. (Soto, 2000, p. 28)

Esta escuela fue inaugurada el 14 de junio de 1842, con sus primeros 28 alumnos; fue ubicada en un edificio cerca de la Plaza de Armas de la capital. En 1845 se transformó en internado y se ubicó en una construcción al lado de la Quinta Normal.

Sarmiento publicó en Chile una de sus principales obras pedagógicas (Sarmiento, 1849), en la cual expone su proyecto de escuela pública, gratuita y laica; en un anexo del libro presenta un proyecto de ley de instrucción primaria, el cual sirvió de base para la ley definitiva aprobada en 1860, siendo presidente Manuel Montt (1851-1861); debido a ella, el estado se hacía responsable de ese nivel educacional para todos los niños y niñas del país.

La tercera institución importante fue la Escuela de Artes y Oficios - EAO ${ }^{7}$, creada por decreto supremo del presidente Manuel Bulnes Prieto (1841-1851) y, manteniéndose como Ministro del área, Manuel Montt Torres el 6 de julio de 1849. Su primer Director fue, también extranjero, el ingeniero y pedagogo francés Jules Jariez. Comenzó sus actividades en el barrio Yungay, calles Catedral con Chacabuco. En 1886 se inició la definitiva sede en la calle Ecuador, la cual aún existe y es considerada monumento nacional desde el primer centenario de su fundación. Los estudiantes recibidos en el siglo 19 eran personas que habían cumplido su educación primaria y allí eran formados en un oficio, egresando con el calificativo de aprendices. Las primeras especialidades eran herrería, carpintería, mecánica y fundición. En 1912 se crearon los grados técnicos, post enseñanza secundaria y desde la década del 60 del siglo pasado se crearon las ingenierías de ejecución (Muñoz et al., 1987).

\footnotetext{
${ }^{5}$ Esta institución fue creada en 1813 por el Director Supremo José Miguel Carrera y constituye el primer paso para establecer una sólida educación pública. Este Instituto ha sido señero en la historia de la República y aún existe.

${ }^{6}$ Futura Escuela Normal para hombres y la primera de 28 escuelas normales creadas posteriormente en diferentes ciudades del país. A la Primera Escuela, se le llamó Escuela Superior José Abelardo Núñez, en honor al gran educador chileno, reestructurador de la misma en la segunda mitad del siglo 19 (Caiceo, 2014, p. 193).

${ }^{7}$ En 1947 se transformó en la Universidad Técnica del Estado, con sedes en varias Provincias, y desde 1981 en la Universidad de Santiago de Chile, reducida sólo a la capital (Muñoz et al., 1987). 
Un cuarto hecho relevante desde la perspectiva laica y educativa fue la creación del Instituto Pedagógico en 1889, con el objeto de formar profesores secundarios. Hasta esa fecha ejercían la docencia clérigos y profesionales de otras áreas: médicos, ingenieros, abogados. En torno a 1870 se dirigió a Europa, y especialmente a Alemania, José Abelardo Núñez, acompañado de Claudio Matte, comisionados por el gobierno de Chile; resultado de aquello fue que vinieron varios profesores alemanes a reforzar la Escuela de Preceptores, llamada ahora Escuela Normal. Algo similar ocurre con Valentín Letelier, quien acompañado por Claudio Matte, viaja a Alemania en 1888 a buscar profesores para formar educadores para la educación secundaria, considerando que a esa época había cerca de 70 liceos fiscales y 122 particulares (Celis, 2015, p. 185). De esta forma, el Presidente José Manuel Balmaceda (1886-1891) encomienda a su ministro Federico Puga para que iniciara el proceso de creación de la institución formadora de profesores secundarios; deja su cargo, pero el sucesor, Julio Bañados dicta el Decreto correspondiente con el n. 1.113 el 29 de abril de 1889, el cual pasó a depender de la Facultad de Filosofía y Humanidades de la Universidad de Chile (Celis, 2015).

Valentín Letelier, entusiasta impulsor de la idea, fundamenta la necesidad de formar profesores por dos razones principales: " $1^{\circ}$ Porque la función docente estaba antes encomendada de una manera casi exclusiva al cuerpo eclesial de cada nación; y $2^{\circ}$ porque reducida la enseñanza a la tarea mecánica de dar y recibir lecciones de memoria, no se necesitaba preparación alguna para ocupar una cátedra de profesor" (Letelier, 1940, p. 18). Pero al recorrer Europa y empaparse del positivismo, toma conciencia de que hay que formar profesores con base científica y ello es deber del estado ${ }^{8}$.

El mencionado decreto señala expresamente en los primeros artículos:

Art. $1^{\circ}$ Créase en Santiago un Instituto Pedagógico destinado a formar profesores de Instrucción secundaria.

Art. $2^{\circ} \mathrm{El}$ Instituto tendrá un Rector que será a la vez profesor.

Art. $3^{\circ} \mathrm{El}$ Instituto se dividirá en dos secciones:

$1^{\circ}$ De Humanidades Superiores y

$2^{\circ}$ De Ciencias

Art. $4^{\circ}$ La Sección de Humanidades Superiores comprenderá cuatro cursos:

1. Castellano y latín

2. Francés y Griego

3. Inglés y Alemán

4. Historia y Geografía

Art. $5^{\circ}$ La Sección de Ciencias comprenderá dos cursos:

1. De matemáticas y

2. De Ciencias Naturales. (República de Chile, 1889, p. 1; Letelier, 1940, p. 38).

El primer rector del Instituto Pedagógico fue el profesor alemán Federico Johow, quien, además como botánico, ejercía las cátedras de ciencias naturales, biología, zoología, botánica e higiene. Salvo Enrique Nercasseau y Morán, que era chileno, y dictaba las cátedras de gramática castellana y latín, todos los demás profesores eran alemanes, a saber, Jorge Enrique Schneider, quien hacía las clases de pedagogía,

${ }^{8}$ Cabe hacer notar que Valentín Letelier publicó una obra sobre filosofía de la educación con una visión positivista en 1892; esa obra fue la primera en su género en lengua hispana. Su influencia fue tal que años después se publicó en Argentina una $2^{\mathrm{a}}$ edición (Letelier, 1927). 
filosofía, lógica, metodología, moral y filosofía de las ciencias ${ }^{9}$; Juan Steffen, dictaba historia y geografía; Federico Hanssen hacía filología, gramática general, lingüística, latín, griego, francés, inglés, alemán, retórica e historia literaria; Reinaldo Von Lilienthal dictaba aritmética, álgebra, geometría, trigonometría y mecánica; Federico Albert era profesor de ciencias naturales (sus especialidades eran botánica, paleontología y ornitología); Alfredo Beutell dictaba las cátedras de química y mineralogía (Letelier, 1940).

Al fundar el estado de Chile durante el siglo 19 las cuatro instituciones mencionadas, afianzó la educación de sus niños, niñas y jóvenes en los diferentes niveles del sistema educativo y, especialmente creando dos instituciones para que se dedicaran a formar profesores normalistas para la educación primaria y profesores de estado para la enseñanza secundaria. Todo ello, a su vez, con una orientación laica, ideas llegadas de Europa que fueron interiorizadas por las clases intelectuales dirigentes, asumidas y puestas en práctica.

En la primera mitad del siglo 19, la educación chilena recibió las influencias filosóficas propias de la época en Europa, las cuales habían ayudado a impulsar la Independencia Americana: La ilustración francesa, el enciclopedismo y el racionalismo; tales influencias provinieron fundamentalmente de Francia y Alemania (Caiceo, 2009). En cambio, desde comienzos del siglo 20 , se dejan de lado esas influencias y durante gran parte de ese período $y$, especialmente las reformas educacionales realizadas ${ }^{10}$, se inspirarán en el educador norteamericano John Dewey, es decir, con una filosofía más bien pragmática. El sistema educativo chileno, por lo tanto, va cambiando de acuerdo a la inspiración pedagógica de cada momento histórico (Caiceo, 1988, p. 95-100).

\section{Principales educadores laicos en el siglo 20 en Chile en el contexto de la pedagogía de Dewey}

Para entender el pensamiento de los autores laicos que se expondrán en este punto, es necesario colocarse en el contexto histórico del Chile de la época; conocer los procesos sociales, políticos, económicos y culturales vigentes. Las personas laicas que se expondrán vivieron todo el proceso de cambio de siglo; en efecto, pasarán ante sus ojos la Revolución de 1891, el debate permanente entre los poderes ejecutivo y parlamentario, el nacimiento de un nuevo siglo, la desilusión de no llegar al primer centenario de la Independencia como país desarrollado -que era lo esperado-, las presiones sociales en el norte del país que motivarán la creación del futuro partido comunista por Luis Emilio Recabarren en 1912, los movimientos militares de 1924, la nueva constitución de 1925 con la separación Iglesia-Estado - lo cual significará colocar en un nivel de igualdad a los poderes civiles y religiosos y no continuar en la constante lucha ideológica entre laicismo

\footnotetext{
${ }^{9}$ Propuso la creación de un Liceo para que los alumnos realizaran sus prácticas, anexo al Instituto Pedagógico. Fue así como14 de julio de 1893 por decreto supremo n. 1.554 se fundó el Liceo de Aplicación, pasando a ser desde 1895 el Rector el propio Schneider (Sánchez et al, 1992).

${ }^{10}$ Durante el siglo 20 hubo cinco hechos relevantes en educación; los tres primeros inspirados directamente en el educador norteamericano; el tercero en los discípulos del mismo, Tyler y Bloom y el quinto ya tendrá otras influencias, además de la anterior, el constructivismo. Esos hechos son la dictación de la Ley de Instrucción Primaria Obligatoria de 1920, la Reforma Educacional de 1927, la Reforma Gradual de la Educación Secundaria de 1945, la reforma educacional de 1965 - la más importante de todas - y la reforma de 1996 (Caiceo, 2012). 
y catolicismo de la segunda mitad del siglo anterior -, el régimen de fuerza del entonces coronel Ibáñez (1927/1931), la llegada al poder del Frente Popular con Pedro Aguirre Cerda en 1938, etc. Con este último hecho, las ideas laicas considerarán las ideas socialistas en boga ${ }^{11}$.

Tal como ya se indicó anteriormente, a partir del siglo 20 , los ojos de los más importantes educadores chilenos laicos, fueron puestos en Estados Unidos y, especialmente con el pensamiento democratizador de la Escuela Nueva en la persona de John Dewey. Varios de ellos fueron a estudiar directamente con el mencionado educador norteamericano. De ellos, se van a destacar a tres, a saber, Darío Salas, Amanda Labarca e Irma Salas.

\section{Darío Salas}

Darío Enrique Salas Díaz (1881-1941) nació en Imperial Bajo, Puerto Saavedra, Región de La Araucanía, el 9 de mayo de 1881. Estudió en la Escuela Normal de Chillán, y se tituló como profesor de Castellano y Francés en el Instituto Pedagógico de la Universidad de Chile. Se destacó como alumno y, por lo mismo, el gobierno lo envió a perfeccionarse a Estados Unidos, obteniendo el grado de Doctor en Pedagogía en la Universidad de Nueva York en 1907. Allí conoció directamente a Dewey; fue su alumno y se empapó de su pensamiento pedagógico. Al regresar al país, Salas traduce al castellano, por primera vez con el nombre literal, My pedagogic creed (1908), obra sintética del pensamiento pedagógico de Dewey, expuesto detalladamente en sus futuras publicaciones. A partir de los principios de la Escuela Nueva, impulsada por su maestro, plantea la importancia de sustituir el modelo alemán de educación por el norteamericano, que se basaba en principios pluralistas, democráticos y eficientes (Caiceo, 2016).

Como pedagogo la meta de Darío Salas fue ampliar y modernizar la educación en Chile, centrándose especialmente en la educación primaria y en la educación popular; en 1910 asumió el cargo de profesor de Pedagogía del Instituto Pedagógico; fue director de la Revista de Instrucción Primaria. Su cargo más importante fue el de director general de Educación Primaria del Ministerio de Educación Pública, pues fue él el principal impulsor de la Ley de Instrucción Primaria Obligatoria de 1920; estuvo en ese cargo hasta 1927. En 1931 fue elegido decano de la Facultad de Filosofía y Ciencias de la Educación de la Universidad de Chile. Falleció 10 años después, en 1941 (Caiceo, 2016).

El mayor aporte de Darío Salas entregado al país para la discusión educacional fue la publicación en 1917 de su principal obra. Este trabajo se pudo publicar en su primera edición gracias a la contribución de la Sociedad Nacional de Profesores y a la Asociación de Educación Nacional (Salas, 1917). La gran obra del pedagogo Salas contiene un diagnóstico de la situación educacional chilena, pero a su vez, una proposición educativa en la que sobresale la importancia de la acción social de las escuelas y la unión entre democracia y educación. En su exposición está claramente presente el pensamiento educativo de John Dewey.

\footnotetext{
${ }^{11}$ Para entender esta afirmación, hay que tener presente que la mayoría de los representantes del laicismo pertenecían al partido político denominado radical. El Frente Popular se conforma con ese partido como eje, pero apoyado por partidos de izquierda marxista, el partido comunista y el partido socialista. Ello significó que se incorporan en el país al grupo laicista personas ligadas a ideas socialistas. 
Los planteamientos de Darío Salas en su libro, serán determinantes para la dictación de la Ley de Instrucción Primaria Obligatoria, la cual se hizo efectiva el 26 de agosto de 1920. El Congreso la despachó con el N. 3.654 y se publicó en el Diario Oficial con el n. 12.755. Esta ley no solo hace obligatoria la educación primaria sino que también el estado se hace responsable de sus costos; será, por tanto, gratuita en los sectores públicos y municipales; gran anhelo de los sectores laicos y defensores del estado docente. En todo caso, una vez más, hubo serias resistencias de parte de los sectores conservadores, quienes no deseaban que el estado obligara a los padres a enviar a sus hijos a la escuela; para su argumentación se basaban en la libertad de enseñanza, tan proclamada por ese sector (Salas, 1967). El debate parlamentario se había iniciado una década antes.

En su libro, en relación a los adultos indica que no solo hay que enseñarles a leer y escribir sino que "hay que entregar ramos que responden a los intereses del alumno, que le son útiles [...] tales como la aritmética y el dibujo especializado [...] geografía nacional, aspectos económicos [...] pero el ramo interesante y útil por excelencia [...] es la higiene" (Salas, 1967, p. 59-60). El énfasis en la educación pragmática es evidente. Respecto a las escuelas de perfeccionamiento propone "el aprendizaje o perfeccionamiento de un oficio y consistiría, por una parte, en labores de taller y, por otra, en el estudio de aquellos ramos física, química, dibujo, modelado [...] - que se relacionen directamente con las antedichas labores [...] aritmética aplicada, contabilidad y correspondencia comercial..."(Salas, 1967, p. 62). Es necesario, a su vez, elevar el nivel cultural; para ello sugiere actividades de "teatros populares[...], de bibliotecas circulantes [...], museos industriales, artísticos, históricos y de ciencias naturales" (Salas, 1967, p. 65). Para preparar a la mujer para su función social debiera darse en cursos especiales ramos como "higiene familiar y doméstica, puericultura, cuidado del enfermo, ciencias y artes domésticas" (Salas, 1967, p. 66).

Finalmente, se refiere en el último capítulo de su obra al tema central de la pedagogía de su maestro: Educación y democracia. Para ello parte por lo más importante de cualquier filosofía de la educación: precisar los fines de la misma, es decir, el "para qué" y "hacia dónde". Su respuesta es tajante: El fin de la educación es social. Ello conduce a la igualdad de oportunidades para todos, para lo cual se necesita una educación universal, obligatoria, con responsabilidad del estado; es él quien la otorga; por lo mismo es una educación común, pero que debe preocuparse de la educación vocacional, según las aptitudes de cada educando. Una educación así concebida va a lograr la democracia, con un cuerpo social sano, con participación, eficiencia económica, virtudes sociales e inteligencia política (Salas, 1967, p. 218).

\section{Amanda Labarca}

Amanda Pinto Sepúlveda nació en Santiago el 5 de diciembre de 1886. Obtuvo el grado de bachiller en Humanidades - prueba que se daba al egresar de la educación secundaria - en 1902. Ello le permitió ingresar al Instituto Pedagógico de la Universidad de Chile al año siguiente. Allí estudió Pedagogía en Castellano, de acuerdo a sus intereses y a la gran afición a la lectura, que la tenía desde pequeña; egresó en 1905 junto a otras dos mujeres. 
En 1910 viajó a los Estados Unidos, acompañada de su esposo, Guillermo Labarca Huberston -de quien tomó sus apellidos- para perfeccionarse en el Teacher's College de la Universidad de Columbia en Nueva York, en donde conoció a Dewey y su pensamiento - el cual será su inspirador educacional a lo largo de su vida académica-; en 1912 se especializó en educación escolar en la Universidad de La Sorbonne en Francia.

De regreso a Chile, junto a otras damas, se preocupó de promover los derechos a la educación y al sufragio para las mujeres (Rojas, 2004). Pero, al mismo tiempo, fue una distinguida educadora, escritora y diplomática. En relación a la educación es importante señalar que en 1931 fue nombrada Directora General de Educación Secundaria. Su labor fue próspera en actividad: continuó con el proyecto de experimentación educacional inspirada en los principios de la Escuela Nueva en la persona de Dewey -, lo que derivó en la fundación, el 28 de marzo de 1932, por decreto n. 604 del Ministerio de Educación, del Liceo Experimental Manuel de Salas. Poseía un Consejo, presidido por ella misma e integrado por Irma Salas, Guillermo Mann, Darío Salas y Arturo Piga. Este Liceo pasó a depender de la Universidad de Chile en 1942, como centro de experimentación pedagógica para la formación de los futuros docentes en su antiguo Instituto Pedagógico (Caiceo, 2015). Esta institución fue creada como un "laboratorio pedagógico destinado a la aplicación y experimentación de nuevas organizaciones, métodos y programas de enseñanza secundaria" (art. 1 en Barrios, 1983, p. 14). Todo lo anterior inspirado en el educador norteamericano.

El planteamiento educativo de Amanda Labarca se inscribe más bien en el ámbito de enunciado de políticas públicas. Está basado en planteamientos teóricos a partir de la filosofía de la educación y de las ciencias fundantes de la educación - psicología del aprendizaje y del desarrollo, sociología educacional, teoría educativa, historia de la educación -, pero para responder en forma práctica a los requerimientos del momento histórico. Sus planteamientos están basados en sus observaciones de la educación, tanto en el extranjero - Estados Unidos y Francia, principalmente -, como en Chile, tomando conciencia de la situación nacional, a partir del estudio de la historia educacional y en el conocimiento empírico directo por el ejercicio de la docencia a nivel del sistema escolar y de la universidad y en el ejercicio de cargos como directora de Liceos, directora de Educación Secundaria y miembro del Consejo Universitario en la Universidad de Chile. En esos planteamientos están presentes especialmente los principios pedagógicos de su maestro norteamericano, con énfasis en la extensión de la educación a las grandes mayorías nacionales y sobre todo a la mujer; en ello se encuentra la concreción de la democracia: a mayor educación, mayor democracia; también desea cambiar el sistema de enseñanza poniendo en práctica el aprender haciendo.

Como impulsora de la pedagogía de Dewey, fue una crítica de la influencia pedagógica alemana en Chile:

En 1885 llegaron los primeros profesores alemanes contratados cuyo método era más científico, aunque alejaba a los alumnos de la realidad autónoma, extranjerizando y aristocratizando el espíritu colegial. Se desconoció al país e intensificó un defecto congénito nuestro, el de sobrevalorar lo extranjero"... "se cometió el error de aplicar el sistema alemán sin adaptarlo a nuestra idiosincrasia" ... "A inmensa distancia de nuestra tradición, de las necesidades de esta raza, tan distinta de la suya, tan diferentemente moldeada en el troquel de la historia, ajenas por 
completo a nuestro espíritu semi-latino, semi-criollo, (los profesores alemanes) pudieron impartir hábilmente ciertas disciplinas, mas, apenas si formaron una que otra discípula, o robustecieron aquellos caracteres que pudieran más tarde influir en la cultura nuestra de manera viva y perenne. (Labarca, 1939, p. 185)

A su vez, como planificadora de la educación, la educadora propone políticas educacionales para impulsar reformas democratizadoras del país:

La reforma tiene que empezar en el Ministerio de Educación y en la Universidad para que ellos la inspiren a las Escuelas Normales, y al Instituto Pedagógico, a los Cursos de Verano o de perfeccionamiento a que concurre el magisterio en ejercicio. Ha de ser una orientación tan convencida, tan leal a los principios democráticos, tan hondamente labrada en la inteligencia, en la voluntad y en la vocación, que sea capaz de imprimir un nuevo espíritu a las generaciones de maestros. (Labarca, 1943, p. 143)

También propone una serie de orientaciones educativas para los adolescentes en su obra de 1943, las cuales persiguen la formación integral de los educandos para su vida personal, familiar, ciudadana y laboral, notándose la influencia de su maestro Dewey y de su pensamiento laico. Ellas son sistematizadas por Luis Mardones (1976, p. 50):

- Adquirir conocimientos acerca de la naturaleza y del hombre.

- Orientar su vida de acuerdo con ideales superiores.

- Encauzar y sublimar sus impulsos y emociones, de modo que enaltezcan su vida.

- Mejorar su salud física, aprender el gusto estético, estimular su bienestar, renovar sus fuerzas para el trabajo.

- Iniciarse en un oficio, industria, comercio, arte, empleo o profesión remunerativa, provechosos para él y su comunidad.

- Realizar, en cuanto hombre o mujer adulta, el tipo de madre o padre que mejor ayude a la sana crianza y a la recta formación espiritual de la generación futura.

- Contribuir al mejoramiento de la cultura, las instituciones políticas y las condiciones sociales de su país.

- Continuar por sí mismo su educación y perfeccionamiento.

- Sentir los deberes de nacionalidad y comprender la solidaridad internacional, llegando a ser un agente activo en la fraternidad y unión de los pueblos.

\section{Irma Salas}

Hija de don Darío Salas, nació en Santiago el 11 de marzo de 1903; su madre, también profesora, Luisa Silva Molina, falleció cuando Irma tenía solo 7 años. Ello significará una mayor unión con su padre, la cual será decisiva en su futuro profesional, pues seguirá los pasos de su progenitor, yendo a estudiar a Estados Unidos en la Universidad de Columbia, doctorándose con Dewey, con la tesis The socio-economic composition of the secondary school population of Chile en $1930^{12}$.

${ }^{12}$ Con este estudio va a difundir la investigación empírica y experimental en Chile. Al regresar a su país realizará varias más y motivará a sus alumnos a realizarlas.

\begin{tabular}{|l|l|l|l|l|l|}
\hline Hist. Educ. (Online) & Porto Alegre & v. 21 & n. 51 & Jan./abr., 2017 & p. 333-350 \\
\hline
\end{tabular}


Sus estudios primarios los realizó en la Escuela Anexa a la Escuela Normal $\mathrm{N}^{\circ} 1$ de Santiago (1911-1913); sus estudios secundarios los realizó en el Liceo de Niñas $N^{\circ} 5$, en donde conoció a Amanda Labarca y ambas trabajarán en el futuro no solo en labores educacionales sino que también en la lucha para obtener los derechos civiles para la mujer. Estudió Pedagogía en Inglés en el Instituto Pedagógico de la Universidad de Chile entre 1920 y 1924 (Sánchez et al., 1992). Falleció el 28 de abril de 1987.

Al regresar con su doctorado al país tuvo una activa participación en la difusión del pensamiento de Dewey en varias actividades en las cuales se nota su influencia; aquí se destacarán solo tres: académica de la Universidad de Chile: como profesora de aula introdujo metodologías renovadas y la investigación educativa; directora del Liceo Experimental Manuel de Salas por 10 años (1933-1943) - fundado por su maestra Labarca, tal como se indicó precedentemente - en donde implementó un verdadero laboratorio pedagógico con los principios de Dewey, destinado a la aplicación y experimentación de nuevas organizaciones, métodos y programas de enseñanza secundaria; presidenta de la Comisión de Renovación Gradual de la Educación Secundaria, por el presidente Juan Antonio Ríos en 1945; se basó en la experiencia del Liceo Manuel de Salas para proponer la creación de nuevos liceos experimentales, a los que se llamó liceos renovados; algunos Liceos creados especialmente para tales efectos fueron: Juan Antonio Ríos, Gabriela Mistral y Darío Salas ${ }^{13}$; otros liceos se adecuaron: Liceo de Niñas de Antofagasta, Liceo N. 6 de Niñas de Santiago, Liceo de Niñas de Concepción y Liceo Coeducacional de Quilpué. La acción de estos liceos se interrumpió en 1953, cuando el presidente Carlos Ibáñez (1952-1958) reformuló los Planes de Estudios de la Educación Secundaria. Sin embargo, gran parte de la nueva metodología introducida y aspectos como el Consejo de Curso, la Orientación y la existencia de profesores orientadores, un nuevo sentido del profesor jefe y el gobierno estudiantil, se mantuvieron. Como puede notarse, toda su acción se centró en la educación pública de inspiración laica.

Un testigo de la labor de Irma Salas en el Liceo Experimental Manuel de Salas, señala que su acción posee un trasfondo:

fundamenta su filosofía educativa en la adhesión a los principios que garantizan la mejor convivencia dentro de una sociedad democrática, principios que permiten al individuo, junto con el ejercicio de las libertades y derechos, proponer el desarrollo de la personalidad, para cumplir con eficiencia, sus responsabilidades frente a la colectividad. (Fuentealba, 1983, p. 75)

Su preocupación por el sistema escolar chileno, especialmente secundario se expresa en la siguiente aseveración de carácter pragmático y científica, inspirada en Dewey:

La actual crisis por la que atraviesa nuestra educación secundaria solo puede ser superada por un planeamiento cuidadoso de todos los aspectos del sistema, que supone una evaluación de sus resultados, la investigación

\footnotetext{
${ }^{13}$ Uno de los Premios Nacionales en Ciencias de la Educación de Chile, Francisco Hernán Vera, fue su director por varios años; otro - Héctor Fernando Gutiérrez - fue orientador; un tercero, Marino Pizarro, fue profesor de castellano. Los tres, a su vez, fueron discípulos de Irma Salas y de mentalidad laicista (Caiceo, 2008). 
y determinación de las necesidades cuantitativas y cualitativas que es preciso satisfacer y, sobre la base de este conocimiento real y objetivo de los hechos, formular y aplicar un conjunto de medidas que tiendan a corregir las deficiencias existentes y hagan posible dirigir inteligentemente el desarrollo escolar. (Salas, 1950, p. 31)

La preocupación de nuestra autora fue sobre diversos temas educativos, entre los cuales se pueden mencionar, el curriculum, características de los agentes educativos, la supervisión escolar, educación permanente, administración escolar y educación latinoamericana. Sobre este último punto, en un contexto de integración y de política pública y laica latinoamericana, propone que

en una materia de tanta importancia para el futuro del continente, convendría empezar a estudiar un programa común de experiencia en el campo de la música, el arte, la literatura de los valores culturales que nos unen en vez de separarnos, lo cual contribuirá que el niño sienta, no solo su calidad de nacional sino también la de latinoamericano, copartícipe de una cultura, ciudadano latinoamericano. Esto podría constituir una medida precursora de la integración a través de la escuela, tarea que supone, como es natural, el cultivo de la vocación americanista del maestro destinado a trabajar estos principios con los alumnos. (Salas, 1983, p. 42)

\section{Presencia de Dewey en los premios nacionales en educación laicos}

Es importante destacar que, en la segunda mitad del siglo 20, se creó en Chile en 1979, a través del D.L. n. 2.838 del 13 de agosto de ese año, el Premio Nacional de Educación ${ }^{14}$; los premiados a la fecha son 18 educadoras o educadores destacados ${ }^{15}$. De los 19 existentes hasta la fecha, solo 6 pertenecen al grupo de inspiración laica, a pesar que, como se ha descrito, la influencia y presencia de los educadores de esta tendencia ha sido mayoritaria en el país; de los 13 restantes, 1 es agnóstica y los otros 12 ligados al cristianismo. Esta situación revela el peso que aún tiene el catolicismo, a pesar de que la educación pública y laica ha predominado desde mediados del siglo 19 en Chile. En todo caso, es necesario señalar que varias de las personas del sector cristiano han colaborado también con la educación pública, pero varias de ellos con un énfasis humanista cristiano, derivado de la reforma de Eduardo Frei Montalva en 1965, quien se inspiró en esa línea de pensamiento. A su vez, el último nombramiento, el de Iván Núñez, también es laicista, está, además, imbuido de ideas socialistas; fue Superintendente de Educación del Presidente Salvador Allende (1970-1973). Sin embargo, este hecho revela una intencionalidad de reconocer el importante rol que el sector laico ha jugado en la educación chilena.

${ }^{14}$ El decreto ley original ha sufrido algunas modificaciones, entre las cuales se encuentran las del D.F.L. N. 1 del 12 de diciembre de 1988 que modifica la constitución del Jurado, el decreto n. 315 del 16 de junio de 1989 que reglamenta las normas de otorgamiento del premio y la ley $n$. 19.169 del 16 de septiembre de 1992 que modificó el título del premio como Premio Nacional de Ciencias de la Educación (Caiceo, 2008).

${ }^{15}$ Ellos son Roberto Munizaga Aguirre (1979); a él le han seguido: Teresa Clerc Mirtin (1981), Luis Gómez Catalán (1983), José Herrera González (1985), Marino Pizarro Pizarro (1987), Eleodoro Cereceda Arancibia (1989), Viola Soto Guzmán (1991), Ernesto Livacic Gazzano (1993), Hugo Montes Brunet (1995), Gabriel Castillo Inzulza (1997), Patricio Cariola Barroilet (1999), Francisco Hernán Vera Lamperein (2001), Mabel Condemarín Grimberg (2003), Héctor Fernando Gutiérrez Muñoz (2005), Ernesto Schiefelbein Fuenzalida (2007), Mario Leyton Soto (2009), Erika Himmel König (2011), Beatrice Ávalos Davidson (2013) e Iván Núñez Prieto (2015).

\begin{tabular}{|l|l|l} 
Hist. Educ. (Online) & Porto Alegre & v. 21
\end{tabular}

\begin{tabular}{l|l} 
v. 21 & n. 51
\end{tabular}

Jan./abr., 2017

p. $333-350$ 
En este grupo de tendencia predominantemente laicista $\mathrm{y}$, pertenecientes a la masonería, se encuentran Roberto Munizaga, Luis Gómez, Marino Pizarro, Hernán Vera y Fernando Gutiérrez. En ellos se percibe claramente la influencia de Dewey, tanto en sus planteamientos teóricos como en su accionar pedagógico, línea que, por lo demás, ha sido la propia de este sector desde comienzos del siglo pasado, tal como se ha descrito precedentemente. En efecto, tanto Gómez como Pizarro, Vera y Gutiérrez tuvieron una activa participación en las reformas educacionales inspiradas en el pensador norteamericano; Gómez fue uno de los ejecutores de la Reforma de 1927 y los otros tres participaron en los Liceos Renovados, aplicando los principios pedagógicos de Dewey. Los cinco, a su vez, estuvieron ligados a Irma Salas - gran exponente laicista, como ya se indicó - ya sea como colegas - Gómez, Munizaga y Pizarro - o alumnos: Pizarro, Vera y Gutiérrez) (Caiceo, 2008)

Respecto a la presencia de Dewey en el pensamiento de algunos de ellos, se puede indicar: Roberto Munizaga es quien más publica, sobre 50 libros, e incursiona no solo en la educación sino que en la filosofía de la educación; sobre esto último indica que las ideas fuerzas que le atribuyó al nuevo tipo de hombre que era necesario que formara la educación secundaria, son tres: "cabeza clara" con "espíritu lúcido": para ello son necesarias las asignaturas propias de las humanidades, especialmente el idioma patrio; las ciencias y las que ayudan a comprender las "ocupaciones útiles"; "un corazón bien puesto" que ayude a formar "personas cultas" con "sensibilidad afinada" y "modales": para lograr esto el Liceo debe transformarse en "un ambiente adecuado"; y "una voluntad firme" con jóvenes "inteligentes", pero de "carácter": para ello, todas las asignaturas deben estar al servicio de los jóvenes para que ellos con su "experiencia de vida" en el "ambiente" del Liceo tengan un "auténtico crecimiento moral" (Munizaga, 1994, p. 127).

En el análisis anterior queda de manifiesto que Munizaga estuvo fuertemente influenciado por Dewey -a quien lo apoda como el filósofo de América- y su Escuela Nueva y, así como Darío Salas en su obra El problema nacional aplicó estos planteamientos a la educación primaria, Munizaga hizo lo propio en relación a la educación secundaria ${ }^{16}$. Sin embargo, su fuerte énfasis en el desarrollo de la inteligencia denota, a su vez, el positivismo de Valentín Letelier, que tanto influirá en él. Marino Pizarro, por su parte, tiene grandes planteamientos humanistas, concibiendo al humanismo como libertario y laico. Asumiendo el planteamiento de la Escuela Nueva, más sus agregados racionalistas e ilustrados, le señala el rol que debe tener la educación: "La educación es, precisamente en la escuela de la vida, la responsable para lograr la justicia, la igualdad, la libertad, la paz, la fraternidad" (Pizarro, 1997, p. 80) Fernando Gutiérrez, a su vez, señala la línea que, a su juicio, tiene el movimiento de la Escuela Nueva en Chile: "La verdad es que hay que reconocer históricamente que todo este movimiento de cambio, de progreso en educación, es laico, y si se quiere ponerle más, apellido Radical" (Gutiérrez, 1997, p. 2) ${ }^{17}$. Con estas últimas palabras de Gutiérrez queda más que claro lo que representa el grupo en que él participa: laicismo masónico.

\footnotetext{
${ }^{16}$ Siguiendo los planteamientos de Dewey, pensaba que universalizando la educación secundaria se afianzaría la democracia.

${ }^{17}$ Entrevista a Gutiérrez, Héctor Fernando, Santiago de Chile, 25 de junio de 1997. El término radical dice relación con el partido político que llevaba ese nombre; sus miembros en su mayoría pertenecían a la masonería y tuvo una gran influencia en la educación pública chilena desde fines del siglo 19 hasta la reforma de 1965. Véase Caiceo (2008).

Hist. Educ. (Online) Porto Alegre

v. 21

ก. 51

Jan./abr., 2017

p. $333-350$
} 


\section{Conclusiones}

Al llegar al final de este artículo, ha quedado claro que los objetivos planteados se han cumplido. En efecto, se ha descrito el origen del laicismo en Chile hacia mediados del siglo 19, subrayando la influencia de intelectuales extranjeros avecindados en el país en dicho proceso de gestación; se han identificado las principales instituciones fundadas por ese sector desde el estado para dar educación a su población en los diferentes niveles primaria, secundaria, técnica y superior-, pero especialmente la creación de dos importantes instituciones señeras en la formación docente en el país: Escuela Normal e Instituto Pedagógico. Se han destacado, a su vez, los principales exponentes laicos desde el sector educacional durante el siglo pasado y se indicó cómo el sistema educacional chileno público, inspirado en el laicismo, pasó de una inspiración europea a una norteamericana. Además, se explicó que el laicismo decimonónico, de raigambre libre pensadora masónica, se nutrió durante el siglo pasado con ideas del socialismo; el reciente galardonado con el Premio Nacional de Educación es una prueba de ello. Aunque redundante, hay que enfatizar que la educación pública chilena se identifica con la educación laica y gratuita durante el período republicano; su desarrollo ha significado un avance significativo a nivel cultural y de alfabetización en el país, ubicándose este siglo 2l a la par en los años de escolaridad, más de 10, a países europeos como España y Portugal.

Se han subrayado, a su vez, las controversias que en distintos momentos se han dado entre el sector inspirado en el laicismo con sectores conservadores, especialmente católicos. También se ha indicado específicamente lo disminuido que ha estado el sector laico a la hora de ser reconocidos sus miembros por la labor e influencia ejercida en Chile, cuando se han otorgado los Premios Nacionales en Educación. En todo caso, lo descrito acerca de los Premios Nacionales en Educación es solo un anticipo de un trabajo mayor a realizar.

\section{Bibliografía}

AEDO-RICHMOND, Ruth. La educación privada en Chile: un estudio histórico-analítico desde el período colonial hasta 1990. Santiago de Chile: Red Internacional del Libro, 2000.

AMUNÁTEGUI, Miguel. De la instrucción primaria en Chile: lo que es y debería ser. Santiago de Chile: Imprenta Del Ferrocarril, 1856.

BARRIOS, Florencia. El Liceo Experimental Manuel de Salas. Santiago de Chile: Universidad de Chile, 1983.

BELLO, Andrés. Discurso pronunciado en la Universidad de Chile el 18 de septiembre de 1843. El Araucano. Santiago de Chile, 1843. Disponible en <http://www.uchile.cl/ portal/presentacion/historia/ 4682/discurso-inaugural>. Consultada el 10 ago. 2015.

BIBLIOTECA NACIONAL DE CHILE. Memoria chilena: el ingreso femenino a la universidad - mujeres y profesionales universitarias (1900-1950). Disponible en $<$ http://www.memoria chilena.cl/602/w3-article-755.html\#>. Consultada el 15 ago. 2015. $2015 a$

BIBLIOTECA NACIONAL DE CHILE. Memoria Chilena. Intelectuales liberales del siglo 19: Sociedad de la igualdad. Disponible en <http://www. memoriachilena.cl/602/w3-article94755.hmtl>. Consultada el 10 ago. 2015b. 
CAICEO, Jaime. Educación en Chile: ¿predominio laicista o cristiano? Boletín de Investigación, v. 6, n. 1-2, Santiago de Chile, 1988, p. 95-100.

CAICEO, Jaime. Presencia de la escuela nueva en los premios nacionales en educación chilenos. História \& Perspectivas, n. 38, 2008, p. 237-270.

CAICEO, Jaime. Estado, iglesia y sistema educativo durante la república en Chile. Revista HISTEDBR On-line, Campinas, n. 35, 2009, p. 3-18.

CAICEO Jaime. Pensamiento Pedagógico en Chile en el siglo 20 y sus Proyecciones. Cadernos de História da Educação, Uberlândia, v. 11, n. 1, 2012, p. 207-226.

CAICEO, Jaime. Influencia educacional de Domingo Faustino Sarmiento en Chile. Revista Dos Puntas, La Serena, año VI, n. 10, 2014, p. 183-203.

CAICEO, Jaime. Amanda Labarca: importante educadora feminista del siglo 20 en Chile. Cadernos de História da Educação, v. 14, n. 3, Uberlândia, 2015, p. 915-930.

CAICEO, Jaime. Surgimiento de los principios de la escuela nueva en Chile y Darío Salas. Revista Educação, Cultura e Sociedade, Sinop, v. 6, n. 1, 2016, p. 124-143.

CELIS, Luis. Historia de la educación en Chile: siglos XVI al XIX. Santiago de Chile: Universidad de Los Lagos, 2015.

COX, Cristián et al. 160 años de educación pública: historia del Ministerio de Educación. Santiago de Chile: Ministerio de Educación, 1997.

DIRECCIÓN DE BIBLIOTECAS, ARCHIVOS Y MUSEOS. Construcción del estado docente en Chile (1860-1920). Disponible en <http://www.museodelaeducacion.cl/648/w3article-25828.html $>$. Consultada el 15 ago. 2015.

FUENTEALBA, Leonardo. El pensamiento pedagógico de irma salas. Revista de Pedagogía Comparada, Madrid, v. XII, n. 52, 1983, p. 70-85.

GUTIÉRREZ, Héctor Fernando. Entrevista. Santiago de Chile, realizada el 25 jun. 1997.

KREBS, Ricardo; CORREA, Sofía; RIQUELME, Alfredo; SERRANO, Sol; ARANCIBIA, Patricia; PINTO, María Eugenia. Catolicismo y laicismo. Santiago de Chile: Nueva Universidad, 1981.

LABARCA, Amanda. Historia de la enseñanza en Chile. Santiago de Chile: Imprenta Universitaria, 1939.

LABARCA, Amanda. Bases para una política educacional. Buenos Aires: Losada, 1943.

LETELIER, Valentín. Filosofía de la educación. Buenos Aires: Cabaut y Cía, 1927.

LETELIER, Valentín. El Instituto Pedagógico. Santiago de Chile: Publicaciones del Instituto Cultural Germano-Chileno, 1940.

MARDONES, Luis. Las ideas educacionales de Amanda Labarca Huberston. Santiago de Chile: Pontificia Universidad Católica de Chile, 1976.

MELLAFE, Rolando; REBOlLEdo, Antonia; CÁRDENAS, Mario. Historia de la Universidad de Chile. Santiago de Chile: Universidad de Chile, 1992.

MUNIZAGA, Roberto (1994). Filosofía de la educación secundaria. Santiago de Chile: Universitaria, 1994.

MUÑOZ, Juan G.; NORAMBUENA, Carmen; ORTEGA, Luis; PÉREZ, Roberto. La Universidad de Santiago de Chile: sobre sus orígenes y su desarrollo histórico. Santiago de Chile: Universidad de Santiago de Chile, 1987. 
PIZARRO, Marino. Sociedad y educación. Santiago de Chile: Talleres de Impresos Universitaria, 1997.

REPÚBLICA DE CHILE. Ministerio de Justicia e Instrucción Pública. Decreto n. 1.113. Santiago de Chile, 29 abr. 1889. Disponible en <http://www.archivonacional.cl/616/w3article-8066.html.> Consultada el 20 ago. 2015.

ROJAS, María Teresa. Amanda Labarca: la participación femenina en la construcción de un discurso educativo. Pensamiento Educativo, v. 34, Santiago de Chile: Pontificia Universidad Católica de Chile, 2004, p. 179-199.

SALAS, Darío. El problema nacional: bases para la reconstrucción de nuestro sistema escolar primario. 1 ed. Santiago de Chile: Asociación de Educación Nacional, 1917.

SALAS, Darío. El problema nacional: bases para la reconstrucción de nuestro sistema escolar primario. 2 ed. Santiago de Chile: Universitaria, 1967.

SALAS, Irma. Consideraciones en torno al desarrollo de la educación secundaria. Revista de Educación, n. 80-81, Santiago de Chile: Ministerio de Educación Pública, 1950, p. 2835.

SALAS, Irma. Homenaje de la corporación de promoción universitaria. Santiago de Chile: CPU, 1983.

SÁNCHEZ, Elena; CAICEO, Jaime; CELIS, Luis; LÓPEZ, Sara; KAGELMACHER, Mónica; POZO, José Miguel; RETAMAL, Myriam. Filósofos y educadores: el pensar Chileno del siglo 20. Santiago de Chile: Facultad de Educación de la Pontificia Universidad Católica de Chile, 1992.

SARMIENTO, Domingo Faustino. De la educación popular. Santiago de Chile: Imprenta de Julio Belin y Compañía, 1849.

SOCÍAS, Miguel. Crónicas sobre la primera logia chilena de habla hispana o un caminar por la historia hacia 1853. Santiago de Chile: Acapulco, 2002.

SOTO, Freddy. Historia de la educación chilena. Santiago de Chile: Centro de Perfeccionamiento, Experimentación e Investigaciones Pedagógicas, 2000.

STUVEN, Ana María. La Generación de 1842 y la conciencia nacional chilena. Revista de Ciencia Política, v. 9, n. 1, Santiago: Pontificia Universidad Católica de Chile, 1987, p. 6180.

ZAPIOLA, José. La sociedad de la igualdad i sus enemigos. Santiago de Chile: Imprenta de Enrique Blanchar-Chessi, 1902.

JAIME CAICEO ESCUDERO es profesor de Filosofía, magister en Educación y doctor en Ciencias de la Educación. Académico de programas de doctorado en la Universidad de Santiago de Chile, en la Universidad Nacional de Cuyo y en la Universidad Católica de Cuyo, las dos últimas en la República Argentina, director del Colegio Santa Isabel de Hungría en La Cisterna, Santiago de Chile; miembro directivo de la Sociedad Chilena de Historia de la Educación.

Dirección: Calle Víctor Raer 5.400 - Las Condes - Santiago de Chile - Chile.

E-mail: jcaiceo@hotmail.com.

Recebido em 4 de outubro de 2016.

Aceito em 21 de novembro de 2016. 